\title{
Awareness of basic life support among Saudi dental students and interns
}

\author{
Hashem Motahir Al-Shamiri ${ }^{1}$, Sadeq Ali Al-Maweri ${ }^{2,3}$, Bassam Shugaa-Addin ${ }^{1}$, \\ Nader Ahmed Alaizari², Abdulrahman Hunaish ${ }^{1,4}$
}

Correspondence: Dr. Hashem Motahir Al-Shamiri

Email: hashem_alshamiri@yahoo.com

'Department of Oral and Maxillofacial Surgery,
Al-Farabi Colleges, Riyadh, Saudi Arabia,
'Department of Oral Medicine and Diagnostic Sciences,
Al-Farabi Colleges, Riyadh, Saudi Arabia,
${ }^{3}$ Department of Oral Medicine, Faculty of Dentistry,
Sanaa University, Sanaa, Yemen,
'Department of Oral Surgery, Ibb University, Ibb, Yemen

\section{ABSTRACT}

Objective: Fatal medical emergencies may occur at any time in the dental clinic. The present study assessed the level of awareness and attitudes toward basic life support (BLS) among Saudi dental students and interns. Materials and Methods: A self-administered questionnaire comprising 23 closed-ended questions was used in this survey. The first part of the questionnaire assessed the demographical profile of the students such as age, gender, and educational level. The second part investigated their knowledge and awareness about BLS. Data from 203 respondents were analyzed using Statistical Package for the Social Studies version 22.0. Results: The response rate was $81.2 \%$. Overall, the respondents showed a low level of knowledge with significant differences between males and females $(<0.001)$. Surprisingly, final-year dental students showed relatively better knowledge than interns though the differences were not statistically significant. Conclusion: The present study demonstrates poor knowledge among dental students regarding BLS and showed the urgent need for continuous refreshing courses for this critical topic.

Key words: Awareness, basic life support, dental students

\section{INTRODUCTION}

Survival following cardiopulmonary arrest is usually not high, and to some degree depends on early interference, quality of cardiopulmonary resuscitation (CPR), and the time of defibrillation. ${ }^{[1-4]}$ Basic life support (BLS) is the base of rescuing lives following cardiac arrest, ${ }^{[5]}$ as it keeps viability until full resuscitation for cardiopulmonary system can be commenced. ${ }^{[6]}$ BLS comprises immediate recognition of cardiac arrest and activation of emergency response system, the early performance of high-quality CPR, and rapid defibrillation. All these steps will prevent the

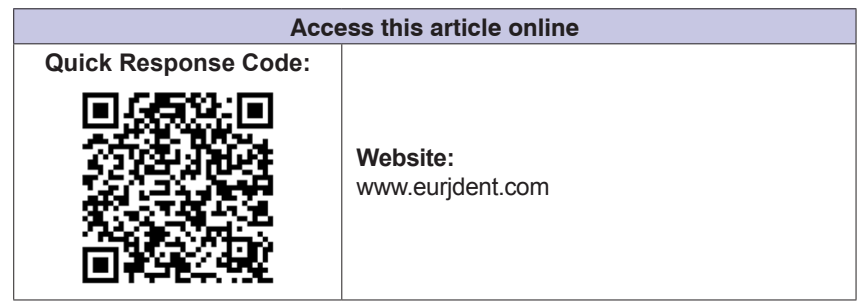

central nervous system from undergoing irreversible damage by hypoxia or anoxia. ${ }^{[7]}$

CPR is controlled by guidelines developed by certain associations such as American heart association, ${ }^{[8]}$ and some other associations in Europe, ${ }^{[9]}$ Singapore, ${ }^{[10]}$ Australia, and New Zealand. . ${ }^{[1]}$ These guidelines are updated regularly to cope with new advances in this field.

Work in the field of dentistry is fraught with many risks leading to life-threatening emergencies.

This is an open access article distributed under the terms of the Creative Commons Attribution-NonCommercial-ShareAlike 3.0 License, which allows others to remix, tweak, and build upon the work non-commercially, as long as the author is credited and the new creations are licensed under the identical terms.

For reprints contact: reprints@medknow.com

How to cite this article: Al-Shamiri HM, Al-Maweri SA, Shugaa-Addin B, Alaizari NA, Hunaish A. Awareness of basic life support among Saudi dental students and interns. Eur J Dent 2017;11:521-5.

DOI: 10.4103/ejd.ejd_44_17 
These conditions may be related to the use of local anesthesia, ${ }^{[12]}$ dental materials with high sensitivity potential, and the fear of unknown surgical operations. Consequently, every dentist must be familiar with various protocols to efficiently manage such emergencies arising in the dental office.

Proper practice of the techniques and maneuvers is mandatory to effectively resuscitate a victim, which requires adequate knowledge and training during dental education years. Many studies have evaluated the level of knowledge about BLS among medical and dental students. However, to our knowledge, none has evaluated the same among dental students in Saudi Arabia. Therefore, this study aimed to assess the level of awareness regarding BLS and the attitude toward CPR-needed victims among Saudi dental students and interns.

\section{MATERIALS AND METHODS}

This study consisted of a cross-sectional survey of undergraduate dental students at the school of Dentistry, Al-Farabi Collages, Riyadh, Saudi Arabia. Clinical dental students (final-year and interns) enrolled during 2015-2016 academic year were eligible to participate $(n=250)$. This study was approved by the Al-Farabi College Institutional Ethical Review Board.

A structured questionnaire was adapted from pretested questionnaires that have been used in similar studies by Chandrasekaran et al. ${ }^{[13]}$ and Reddy et al. ${ }^{[14]}$ with some modifications to accommodate the student's educational level. Before submitting the questionnaire, a pilot study was performed on a random sample of the students $(n=20)$, and the questionnaire was modified according to the feedback obtained.

Students were asked to fill out the anonymous self-administered questionnaire at the end of the lectures and sometimes during the clinical sessions without discussion for $15 \mathrm{~min}$. Students who agreed to participate in the study and signed a consent form before answering the questionnaire.

The self-administered questionnaire comprised of 23 closed-ended questions divided into two parts. The first part assessed the demographic profile of students such as age, gender, and educational level. The second part investigated the participants' knowledge and awareness regarding BLS.
For a better assessment, the knowledge scores were categorized into three divisions as follows: inadequate $(<50 \%)$, satisfactory $(51 \%-75 \%)$, and adequate $(>75 \%)$.

Statistical Package for Social Studies version 22.0 (IBM Corporation, Chicago, IL, USA) was used for data entry and descriptive statistics including frequencies and proportions. Chi-squared test was used to assess statistical significance. A $P<0.05$ was considered statistically significant.

\section{RESULTS}

Out of the 250 dental students participated in the survey, 203 (145 final-year students and 58 interns) returned the questionnaires, giving a response rate of $81.2 \%$.

Table 1 summarizes the demographic data of the participants. Around $52 \%$ were males and the majority were final-year dental students $(71.4 \%)$.

Overall, the respondents showed a poor level of knowledge with respect to most of the questions; the proportion of correct answers varied greatly, ranging from $7.4 \%$ to $93 \%$, with significant differences between males and females [Table 2].

Table 3 illustrates the mean knowledge scores by gender, age, and the academic level. Overall, more than half of the respondents showed inadequate knowledge (scoring $<50 \%$ ). Comparing the mean knowledge scores, males showed higher mean scores $(45.41 \pm 10)$ than females $(42.31 \pm 16.3)$, and the difference was statistically significant $(P<0.01)$. With reference to age groups and educational levels, the mean knowledge scores were comparable, with no significant difference between the groups [Table 3].

\begin{tabular}{lc}
$\begin{array}{l}\text { Table 1: Demographic distribution of the study } \\
\text { population (\%) }\end{array}$ \\
\hline Variables & $\boldsymbol{n}(\%)$ \\
\hline Gender & \\
$\quad$ Male & $97(47.8)$ \\
$\quad$ Female & $106(52.2)$ \\
Age groups (years) & \\
$\quad<25$ & $141(69.5)$ \\
$26-35$ & $61(30)$ \\
$>35$ & $1(0.5)$ \\
Educational levels & \\
$\quad$ Final year & $145(71.4)$ \\
Internship & $58(28.6)$ \\
\hline
\end{tabular}


Al-Shamiri, et al:: Awareness of BLS among dental students and interns

\begin{tabular}{|c|c|c|c|c|c|}
\hline \multirow{2}{*}{$\begin{array}{l}\text { Question } \\
\text { number }\end{array}$} & \multirow[t]{2}{*}{ Questions } & \multicolumn{2}{|c|}{ Gender, $\boldsymbol{n}(\%)$} & \multirow[t]{2}{*}{ Total } & \multirow[t]{2}{*}{$P$} \\
\hline & & Male & Female & & \\
\hline 1 & Abbreviation of "BLS"? & $85(87.6)$ & $102(98.1)$ & $187(93)$ & $0.004^{*}$ \\
\hline 2 & $\begin{array}{l}\text { Find someone unresponsive in the middle of the } \\
\text { road, what will be your first response? }\end{array}$ & $6(6.2)$ & $38(35.8)$ & $44(21.7)$ & $0.000^{*}$ \\
\hline 3 & $\begin{array}{l}\text { If you confirm somebody is not responding to you even after shaking } \\
\text { and shouting at him, what will be your immediate action? }\end{array}$ & $1(1)$ & $14(13.2)$ & $15(7.4)$ & $0.000^{*}$ \\
\hline 4 & Location of chest compression? & $66(68)$ & $46(44.7)$ & $112(56)$ & $0.003^{*}$ \\
\hline 5 & Location for chest compression in infants? & $70(72.2)$ & $62(59)$ & $132(65.3)$ & $0.005^{\star}$ \\
\hline 6 & $\begin{array}{l}\text { If you do not want to give mouth-to-mouth CPR, } \\
\text { the following can be done "except"? }\end{array}$ & $93(95.9)$ & $70(68)$ & $163(81.5)$ & $0.000^{*}$ \\
\hline 7 & Rescue breathing in infants? & $74(76.3)$ & $37(35.2)$ & $111(55)$ & $0.000^{*}$ \\
\hline 8 & Depth of compression in adults during CPR? & $5(5.2)$ & $17(16)$ & $22(10.8)$ & $0.000^{*}$ \\
\hline 9 & Depth of compression in children during CPR? & $11(11.6)$ & $51(49)$ & $62(31.2)$ & $0.000^{*}$ \\
\hline 10 & Depth of compression in neonates during CPR? & $61(63.5)$ & $43(43.4)$ & $104(53.3)$ & $0.001^{*}$ \\
\hline 11 & Rate of chest compression in adult and children during CPR? & $84(87.5)$ & $43(41.3)$ & $127(63.5)$ & $0.000^{*}$ \\
\hline 12 & Ratio of CPR, single rescuer in adults is? & $8(8.2)$ & $55(53.4)$ & $63(31.5)$ & $0.000^{*}$ \\
\hline 13 & In a newborn, the chest compression and ventilation ratio is? & $4(4.3)$ & $11(11)$ & $15(7.7)$ & $0.000^{*}$ \\
\hline 14 & Abbreviation AED stands for? & $66(68)$ & $47(44.8)$ & $113(55.9)$ & $0.006^{*}$ \\
\hline 15 & Abbreviation EMS stands for? & $53(54.6)$ & $63(60.6)$ & $116(57.7)$ & $0.000^{*}$ \\
\hline 16 & $\begin{array}{l}\text { If you and your friend are having food in a canteen and suddenly your friend } \\
\text { starts expressing symptoms of choking, what will be your first response? }\end{array}$ & 0 & $22(21)$ & $22(10.9)$ & $0.000^{*}$ \\
\hline 17 & $\begin{array}{l}\text { You are witnessing an infant who suddenly started choking } \\
\text { while he was playing with the toy, you have confirmed that he is } \\
\text { unable to cry (or) cough, what will be your first response? }\end{array}$ & $10(10.3)$ & $54(51.4)$ & 64 (31.7) & $0.000^{*}$ \\
\hline 18 & $\begin{array}{l}\text { You are witnessing an adult unresponsive victim who has been } \\
\text { submerged in fresh water and just removed from it. He has spontaneous } \\
\text { breathing, but he is unresponsive. What is the first step? }\end{array}$ & $3(3.1)$ & $30(28.6)$ & $33(16.4)$ & $0.000^{*}$ \\
\hline 19 & $\begin{array}{l}\text { You noticed that your colleague has suddenly developed slurring of speech } \\
\text { and weakness of right upper limb. Which one of the following can be done? }\end{array}$ & 69 (71.1) & $20(2.9)$ & $89(44.1)$ & $0.000^{*}$ \\
\hline 20 & $\begin{array}{l}\text { A 50-year-old gentleman with retrosternal chest discomfort, profuse } \\
\text { sweating, and vomiting. What is next? }\end{array}$ & $90(92.8)$ & $64(61.0)$ & $154(76.2)$ & $0.000^{*}$ \\
\hline
\end{tabular}

\begin{tabular}{|c|c|c|c|c|c|}
\hline \multirow[t]{2}{*}{ Variables } & \multicolumn{3}{|c|}{ Knowledge scores, $n(\%)$} & \multirow[t]{2}{*}{ Mean knowledge scores (\%) } & \multirow[t]{2}{*}{$P$} \\
\hline & Inadequate $(<50)$ & Satisfactory (51-75) & Adequate (>75) & & \\
\hline \multicolumn{6}{|l|}{ Gender } \\
\hline Males & $52(53.6)$ & $45(46.4)$ & 0 & $45.41 \pm 10.0$ & $0.003^{*}$ \\
\hline Females & $74(69.8)$ & $28(26.4)$ & $4(3.8)$ & $42.31 \pm 16.3$ & \\
\hline \multicolumn{6}{|c|}{ Age groups (years) } \\
\hline$<25$ & $85(60.3)$ & $53(37.6)$ & $3(2.1)$ & $43.94 \pm 13.9$ & 0.889 \\
\hline $26-35$ & $40(65.6)$ & $20(32.8)$ & $1(1.6)$ & $43.44 \pm 13.6$ & \\
\hline$>35$ & $1(100)$ & 0 & 0 & 45.0 & \\
\hline \multicolumn{6}{|c|}{ Educational levels } \\
\hline Final-year & $85(58.6)$ & $57(39.3)$ & $3(2.1)$ & $43.97 \pm 13.5$ & 0.275 \\
\hline Internship & $41(70.7)$ & $16(27.6)$ & $1(1.7)$ & $43.36 \pm 14.5$ & \\
\hline
\end{tabular}

\section{DISCUSSION}

Medical emergencies that threaten the life may occur at any time in the dental clinic. It may occur as a result of local anesthesia administration, the fear of unknown surgical procedures, or due to other reasons. ${ }^{[12]}$ Therefore, the knowledge about the chain of survival can improve the chances of survival and recovery in conditions such as heart attack, stroke, or any other emergencies. This chain includes immediate recognition of cardiac arrest and activation of the emergency response system, early $\mathrm{CPR}$, rapid defibrillation, and effective advanced life support with postcardiac arrest care. ${ }^{[15]}$ This study was 
planned to examine BLS knowledge among interns and final-year dental students at Alfarabi Collages of dentistry and nursing.

Overall, the dental students in the present survey showed an inadequate level of knowledge of BLS. This result is in agreement with other previous studies such as Chandrasekaran et al., ${ }^{[13]}$ Reddy et al., ${ }^{[14]}$ and Owojuyigbe et al., ${ }^{[16]}$ who concluded that dental students' knowledge of BLS was very poor before the BLS training. However, our results are different from a study conducted by Narayan $\mathrm{al}^{[17]}$ in which dental interns showed an adequate level of knowledge.

In one study conducted among dental students in India, only $26.9 \%$ and $73.1 \%$ of males and females, respectively, knew the abbreviation of "BLS," whereas, in our study, the figures were much higher $(87.6 \%$ and $98.1 \%$, among males and females, respectively). ${ }^{[14]}$ The correct response of participants to the item "chocking in adults" in the present study was $10.9 \%$. This figure is comparable to the $16.8 \%$ and $19.8 \%$ reported by Reddy et al. ${ }^{[14]}$ and Roshana et al., ${ }^{[18]}$ respectively.

This study showed a slight difference in the mean knowledge score between males $(45.41 \%)$ and females $(42.31 \%)$, with statistically significant difference (0.003). This finding contradicts the findings by some studies ${ }^{[14,19]}$ which reported that females revealed a higher mean score as compared to males; this may be attributed to the difference in sample size with regard to gender between the two studies, as well as to the cultural barriers imposed on female gender in Saudi Arabia. This fact was proven in other subjects in a similar students' sample. ${ }^{[20]}$

In the current study, it was noted that both final-year students and interns had inadequate knowledge with nearly similar findings ( $43.97 \%$ vs. $43.36 \%)$. Nevertheless, the final-year dental students $(39.3 \%)$ showed better satisfactory (between $51 \%$ and $75 \%$ ) scores in comparison to the interns $(27.6 \%)$. This finding is compatible with another study by Reddy et al., ${ }^{[14]}$ which showed better knowledge scores among undergraduate students. This finding can be explained by the fact that the topics of CPR and medically compromised emergencies are included in the $5^{\text {th }}$ year (before final-year) curriculum, so final-year students still memorize the information far better than their interns counterparts, emphasizing the need for continuous refreshing courses about these critical topics. Further, these results could be attributed to inadequate didactic and practical training regarding BLS in dental schools. This fact was emphasized by recent studies that reported that CPR training and short courses had a positive impact in self-assurance toward BLS. ${ }^{[16,21]}$

It has been reported that all observational studies such as cross-sectional surveys are prone to limitation and bias. ${ }^{[22]}$ This study has some limitations that should be taken into consideration. One possible limitation is the likelihood of selection bias given that dental students who chose to participate in the survey may be keener interested or concerned with CPR than those who did not participate. Therefore, the results are likely not generalizable to nonrespondents. In addition, a general limiting characteristic of self-reporting survey is the probability of socially acceptable responding, ${ }^{[23]}$ and therefore the results may not necessarily fully reflect student's real knowledge and daily professional practice. Nonetheless, despite these limitations, the study provides some important information about Saudi dental students' knowledge and attitude regarding principles of BLS.

\section{CONCLUSION}

The findings of the present study demonstrates poor knowledge among dental students regarding BLS and showed the urgent need for continuous refreshing courses for this critical topic.

\section{Financial support and sponsorship \\ Nil.}

\section{Conflicts of interest}

There are no conflicts of interest.

\section{REFERENCES}

1. Ritter G, Wolfe RA, Goldstein S, Landis JR, Vasu CM, Acheson A, et al. The effect of bystander CPR on survival of out-of-hospital cardiac arrest victims. Am Heart J 1985;110:932-7.

2. Wenzel V, Lehmkuhl P, Kubilis PS, Idris AH, Pichlmayr I. Poor correlation of mouth-to-mouth ventilation skills after basic life support training and 6 months later. Resuscitation 1997;35:129-34.

3. Wik L, Steen PA, Bircher NG. Quality of bystander cardiopulmonary resuscitation influences outcome after prehospital cardiac arrest. Resuscitation 1994;28:195-203.

4. Gwinnutt CL, Columb M, Harris R. Outcome after cardiac arrest in adults in UK hospitals: Effect of the 1997 guidelines. Resuscitation 2000;47:125-35.

5. Field JM, Hazinski MF, Sayre MR, Chameides L, Schexnayder SM, Hemphill R, et al. Part 1: Executive summary: 2010 American Heart Association Guidelines for Cardiopulmonary Resuscitation and Emergency Cardiovascular Care. Circulation 2010;122 18 Suppl 3:S640-56

6. Graham CA, Guest KA, Scollon D. Cardiopulmonary resuscitation Paper 2: A survey of basic life support training for medical students. J Accid Emerg Med 1994;11:165-7.

7. Sasson C, Rogers MA, Dahl J, Kellermann AL. Predictors of survival from out-of-hospital cardiac arrest: A systematic review and meta-analysis. Circ Cardiovasc Qual Outcomes 2010;3:63-81. 


\section{Al-Shamiri, et al.: Awareness of BLS among dental students and interns}

8. Spencer B, Chacko J, Sallee D; American Heart Association. The 2010 American Heart Association guidelines for cardiopulmonary resuscitation and emergency cardiac care: An overview of the changes to pediatric basic and advanced life support. Crit Care Nurs Clin North Am 2011;23:303-10.

9. Sandroni C, Nolan J; European Resuscitation Council. ERC 2010 guidelines for adult and pediatric resuscitation: Summary of major changes. Minerva Anestesiol 2011;77:220-6.

10. Lim SH. Basic cardiac life support: 2011 Singapore guidelines. Singapore Med J 2011;52:538-42.

11. Australian Resuscitation Council; New Zealand Resuscitation Council. Basic life support: Cardiopulmonary resuscitation. ARC and NZRC Guideline 2010. Emerg Med Australas 2011;23:259-60.

12. Grzanka A, Misiolek H, Filipowska A, Miskiewicz-Orczyk K, Jarzab J. Adverse effects of local anaesthetics - Allergy, toxic reactions or hypersensitivity. Anestezjol Intens Ter 2010;42:175-8.

13. Chandrasekaran S, Kumar S, Bhat SA, Saravanakumar, Shabbir PM, Chandrasekaran V. Awareness of basic life support among medical, dental, nursing students and doctors. Indian J Anaesth 2010;54:121-6.

14. Reddy S, Doshi D, Reddy P, Kulkarni S, Reddy S. Awareness of basic life support among staff and students in a dental school. J Contemp Dent Pract 2013;14:511-7.

15. Businger A, Rinderknecht S, Blank R, Merki L, Carrel T. Students' knowledge of symptoms and risk factors of potential life-threatening medical conditions. Swiss Med Wkly 2010;140:78-84.
16. Owojuyigbe AM, Adenekan AT, Faponle AF, Olateju SO. Impact of basic life support training on the knowledge of basic life support in a group of Nigerian Dental Students. Niger Postgrad Med J 2015;22:164-8.

17. Narayan DP, Biradar SV, Reddy MT, Bk S. Assessment of knowledge and attitude about basic life support among dental interns and postgraduate students in Bangalore city, India. World J Emerg Med 2015;6:118-22.

18. Roshana S, Kh B, Rm P, Mw S. Basic life support: Knowledge and attitude of medical/paramedical professionals. World J Emerg Med 2012;3:141-5.

19. Chew KS, Yazid MN. The willingness of final year medical and dental students to perform bystander cardiopulmonary resuscitation in an Asian community. Int J Emerg Med 2008;1:301-9.

20. Al-Shamiri HM, Alaizari NA, Al-Maweri SA, Tarakji B. Knowledge and attitude of dental trauma among dental students in Saudi Arabia. Eur J Dent 2015;9:518-22

21. Kobras M, Langewand S, Murr C, Neu C, Schmid J. Short lessons in basic life support improve self-assurance in performing cardiopulmonary resuscitation. World J Emerg Med 2016;7:255-62.

22. Lu CY. Observational studies: A review of study designs, challenges and strategies to reduce confounding. Int J Clin Pract 2009;63:691-7.

23. Boroumand S, Garcia AI, Selwitz RH, Goodman HS. Knowledge and opinions regarding oral cancer among Maryland dental students. J Cancer Educ 2008;23:85-91. 